\title{
ETS transcription factors and prostate cancer: The role of the family prototype ETS-1 (Review)
}

\author{
DAVID ADLER and NICOLAS WERNERT \\ Institute of Pathology, University Hospital Bonn, D-53127 Bonn, Germany
}

Received November 14, 2011; Accepted December 22, 2011

DOI: 10.3892/ijo.2012.1380

\begin{abstract}
The ETS family of transcription factors is known to play important roles in various biological processes such as development, differentiation, proliferation, apoptosis, migration, tissue remodeling, invasion and angiogenesis in various cell types including B cells, endothelial cells, fibroblasts as well as diverse neoplastic cells. In prostate cancer, recurrent gene fusions involving members of the ETS family are frequently reported. ETS-1, the prototype of the ETS family, is expressed in different cell types and is known to play various roles during both physiological and pathological conditions. In this review, we focus on studies investigating the role of ETS-1 in prostate cancer.
\end{abstract}

\section{Contents}

1. Introduction

2. ETS gene fusions in prostate cancer

3. Expression of the ETS family in prostate cancer

4. The roles of the ETS-family prototype ETS-1 in prostate cancer

5. ETS-1, a potential regulator of the ETS-family in prostate cancer

6. Conclusion

\section{Introduction}

The ETS- 1 gene was first identified as the cellular proto-oncogene of the retroviral $\mathrm{v}-E T S$ oncogene that is associated with $\mathrm{v}-M Y B$ in the avian leukemia retrovirus E26 (E twenty-six-specific, ETS-1) (1-3). ETS-1 is expressed in different cell types and is reported to play various roles during physiological (e.g., embryonic development, lymphoid differentiation, vascular development, hematopoietic differentiation), as well as pathological conditions

Correspondence to: Professor Nicolas Wernert, Institute of Pathology, University Hospital Bonn, Sigmund-Freud-Str. 25, D-53127 Bonn, Germany

E-mail: nicolas.wernert@ukb.uni-bonn.de

Key words: ETS-1, transcriptional regulation, prostate cancer (reviewed in refs. 4,5). ETS-1 is implicated in tumor vascularization and angiogenesis, as well as in contributing to tumor proliferation and invasion by acting within both neoplastic cells and fibroblasts of the tumor stroma (6-15).

ETS-1 is highly conserved among species, and is considered to be the prototype and the founding members of the ETS gene family of transcription factors (16-18). The ETS family of transcription factors is characterized by an evolutionary highly conserved DNA-binding domain, the ETS domain, which consists of about 80 amino acids with 4 tryptophan repeats that recognizes DNA sequences containing a GGAA/T core motif (reviewed in refs. 5,19). Phylogenetic analysis of the ETS domain identified subfamilies of more highly related members (20). Different ETS members have various functions which may be due to their binding preferences for distinct flanking sequences that could facilitate their binding specificity (20). Moreover, overlapping functions of ETS members, as well as redundant occupancy at proximal regulatory gene regions have been reported $(20,21)$. Therefore, trans-activation or trans-repression of genes could be determined by the dynamic binding equilibrium, the activity of the ETS trans-activation domains, as well as the ternary complex formation of different ETS members and other transcription factors (22).

In humans, the ETS family consists of 27 members (23) and is known to play important roles in a wide range of processes (e.g., development, differentiation, proliferation, apoptosis, migration, tissue remodeling, invasion and angiogenesis) in different cell types such as B cells, endothelial cells, fibroblasts and neoplastic cells (24-29).

\section{ETS gene fusions in prostate cancer}

Recurrent gene fusions between the androgen-regulated prostate-specific serine protease TMPRSS2 gene, and several members of the ETS family of transcription factors (ETV-1, $E T V-4, E T V-5$, and most commonly $E R G$ ) are frequently found in prostate cancer (reviewed in refs 30-32). Such translocations lead to increased expression of the rearranged ETS members in response to androgens (reviewed in ref. 31). Some studies have suggested that ETS rearrangements are sufficient for initiation of prostate neoplasia, while other studies have indicated that the rearrangements may foster progression rather than initiation events in prostate tumorigenesis $(33,34)$.

While the TMPRSS2-ERG fusions are the most predominant in prostate cancer (15-80\%), other rare ETS gene rearrange- 


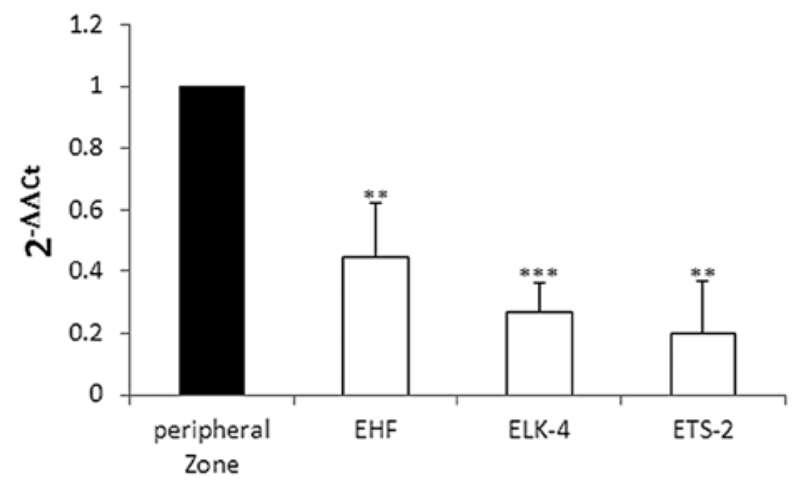

Figure 1. Expression analysis of the ETS-family members in prostate cancer tissues. Expression pattern of all 27 ETS transcription factors by quantitative RT-PCR (qRT-PCR) using RNA extracted from laser microdissected glands of the normal prostate proper (or the peripheral zone) and tumor glands. EHF, ELK4, and ETS2 show significant down-regulation in the tumor glands compared to the normal glands. Significance was calculated with the Student's t-test. $\mathrm{P}$-values are indicated as ${ }^{* * * *} \mathrm{P}<0.001,{ }^{* * *} \mathrm{P}<0.01$ and ${ }^{*} \mathrm{P}<0.05(45)$.

ments involving primarily $E T V-1$, as well as ETV-4 and ETV-5 constitute approximately $1-10 \%$ of cases (reviewed in refs. $31,32,35)$. Notably, investigations of the ERG rearrangement in both primary prostate cancer and metastases have suggested that the ERG rearrangement status is a clonal expansion event during prostate cancer progression (36-39).

Several studies have been undertaken to understand the role of these ETS genes and fusions in prostate cancer (33,40-43). For instance, knockdown of $E R G$ in prostate cancer cell lines was reported to induce morphological changes and to lead to the inhibition of cell growth in both cell culture and mice, whereas overexpression of ERG leads to an increase in cell invasion (40). Moreover, overexpression of TMPRSS2-ERG in primary or immortalized benign prostate epithelial cells was able to induce invasion, but unable to increase proliferation or anchorage-independent growth (reviewed in ref. 41). Studies investigating the role of ETV-1 have shown that ETV-1 inhibition in prostate cancer cells leads to a reduction in invasion (44), while overexpression results in an increase in cell invasion (33). Other studies examining the roles of ETV-4 and ETV-5, have shown that ETV-4 is required for anchorage-independent growth and cell proliferation gene expression program in prostate cancer cell lines (42), whereas ETV-5 ectopic overexpression in benign prostate cells induces invasion (43).

\section{Expression of the ETS family in prostate cancer}

The expression of some of the ETS family members in prostate cancer tissues was reported using immunohistochemistry, RT-PCR, microarrays, and/or in situ hybridization (reviewed in ref. 41). Some of the ETS genes such as ETS-1, FLI1, ERG, $E L F-1$ and $P D E F$ were found to be overexpressed in tumors, while others such as ETV-4 and ELK-1 were reported to show negative staining in prostate cancer tissues (reviewed in ref. 41).

In order to have a complete analysis of the expression of the ETS family members in prostate cancer, we have recently reported the expression pattern of all 27 ETS transcription factors by quantitative RT-PCR (qRT-PCR) using RNA extracted from laser microdissected glands of the normal prostate proper (or the peripheral zone) and moderately differentiated tumor glands from patients who had undergone radical prostatectomy (Fig. 1) (45). Our analysis revealed that only 3/27 ETS family members, EHF, ELK-4 and ETS-2 exhibit significant differences in expression between normal and tumor glands (Fig. 1).

In a subsequent study using a larger number of patients which included both moderately and poorly differentiated tumor glands, we examined by qRT-PCR the expression of the ETS gene ERG and that of TMPRSS 2 in the moderately/poorly differentiated tumor glands compared to normal glands (46), as recurrent gene fusions between TMPRSS 2 and ERG are the most commonly found ETS gene fusions in prostate cancer (15-80\%) (reviewed in refs. 30-32). Our study revealed the up-regulation of both ERG and TMPRSS2 in tumor glands compared to the corresponding normal glands (Fig. 2) (46) which supports previous reports (41).

In parallel with investigating the expression pattern of the ETS family in prostate cancer tissues, we examined the expression pattern of all 27 ETS members using qRT-PCR in the androgen-sensitive $\mathrm{VCaP}$ and $\mathrm{LNCaP}$, and the androgeninsensitive PC3 and DU-145 prostate cancer cell lines (45). We found a unique expression pattern of the ETS family members among the four cell lines (Fig. 3).
A

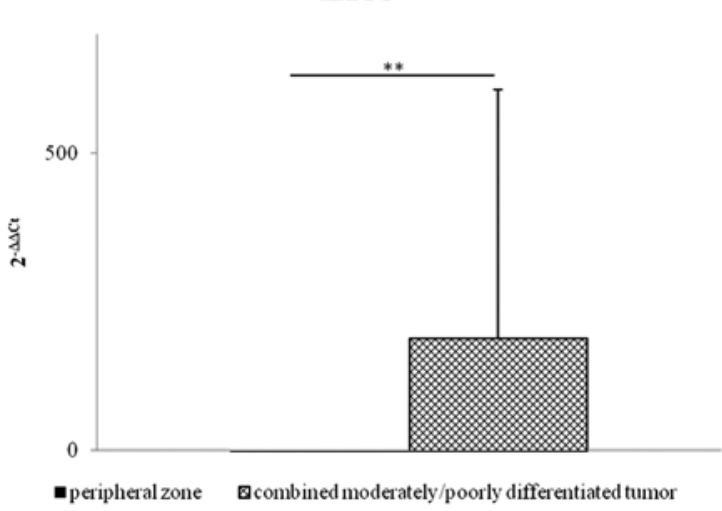

B

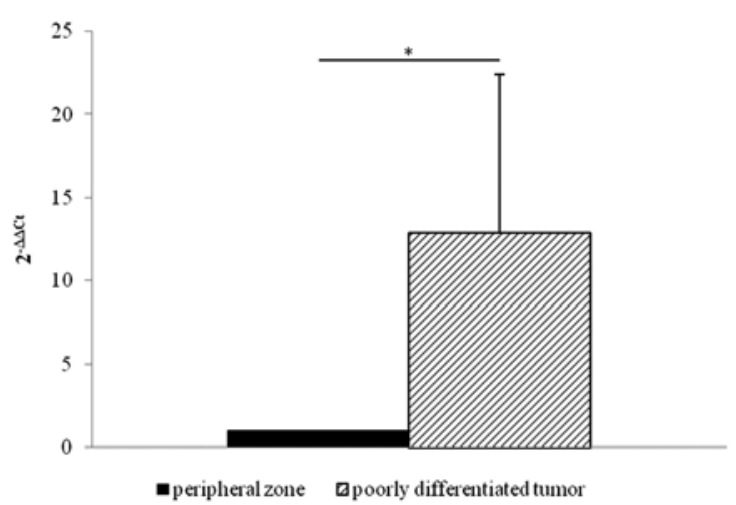

Figure 2. Expression of $E R G$ and TMPRSS2 in lasermicrodissected glands of the prostate proper and in prostate carcinoma glands. The relative expression of $E R G$ (A) and TMPRSS2 (B) was measured by quantitative RT-PCR in prostate carcinoma glands compared to normal glands of the prostate proper. Significance was calculated with the Student's t-test. P-values are indicated as ${ }^{* * *} \mathrm{P} 0.001,{ }^{* * *} \mathrm{P}<0.01$ and ${ }^{*} \mathrm{P}<0.05(46)$. 

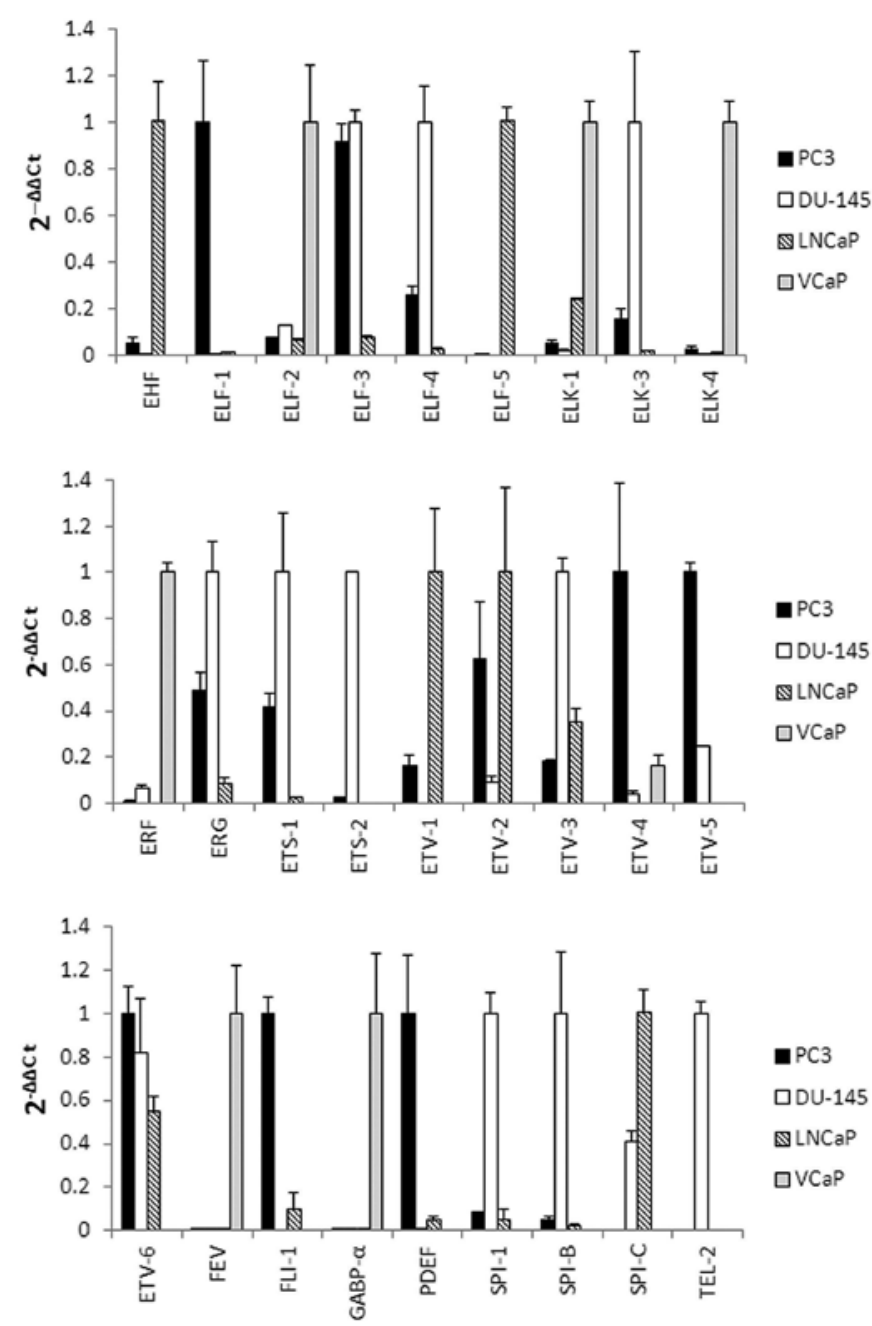

Figure 3. Expression profiles of ETS family members in prostate cancer cell lines. The expression of the 27 ETS family members was measured by qRT-PCR in LNCaP, VCaP, PC3 and DU-145 prostate cancer cell lines (45).

The expression level of a given ETS family member in each of the cell lines may reflect the unique role that ETS member plays in that particular cell line. Another plausible explanation for the differences in the expression pattern of the ETS family members among the four cell lines may be due to the distinct biological properties of each cell line, as each cell line was derived from a different origin (45). For instance, DU-145 cells were derived from a brain metastasis, PC3 cells from an advanced androgen-independent bone metastasis, $\mathrm{LNCaP}$ cells from a supraclavicular lymph node metastasis, and $\mathrm{VCaP}$ cells from a metastatic lesion to a lumbar vertebral body of a patient with hormone refractory prostate cancer (45).

Finally, the role of the ETS genes, EHF, ETS-2 and ERG which we have identified in prostate cancer tissues $(45,46)$, have been investigated in prostate cancer cell lines $(40,47-49)$. Knockdown of EHF in prostate cancer cell lines has been shown to inhibit cell proliferation and to induce a premature cellular senescence (47). Studies investigating the role of ETS-2 have reported that blockade of ETS-2 function reduces transformed properties of prostate cancer cells (48), and down-regulation of ETS-2 expression leads to growth inhibition and apoptosis in prostate cancer cells (49). Lastly, knockdown of $E R G$ was reported to induce morphological changes and result in cell growth inhibition in both cell culture and mice, whereas overexpression of $E R G$ resulted in an increase in cell invasion (40).

\section{The roles of the ETS-family prototype ETS-1 in prostate cancer}

As mentioned in the previous section, ETS-1 is expressed in different cell types and is reported to play various roles during both physiological and pathological conditions (reviewed in refs. $4,5)$.

In prostate cancer, ETS-1 has been reported to be overexpressed in latent and clinically manifest carcinomas and a strong expression of ETS-1 has been associated with poor tumor differentiation (12). Additionally, we have recently reported that ETS-1 is up-regulated in prostate carcinoma glands compared to normal glands (50).

As ETS-1 has been shown previously to promote proliferation, migration and invasion in different neoplastic cells such as melanoma, HeLa and glioma cells (26-28), we have recently examined whether ETS-1 has a similar effect upon these biological properties in prostate cancer cells (29). We established two stable PC3 prostate cancer cell line cultures by transfection with

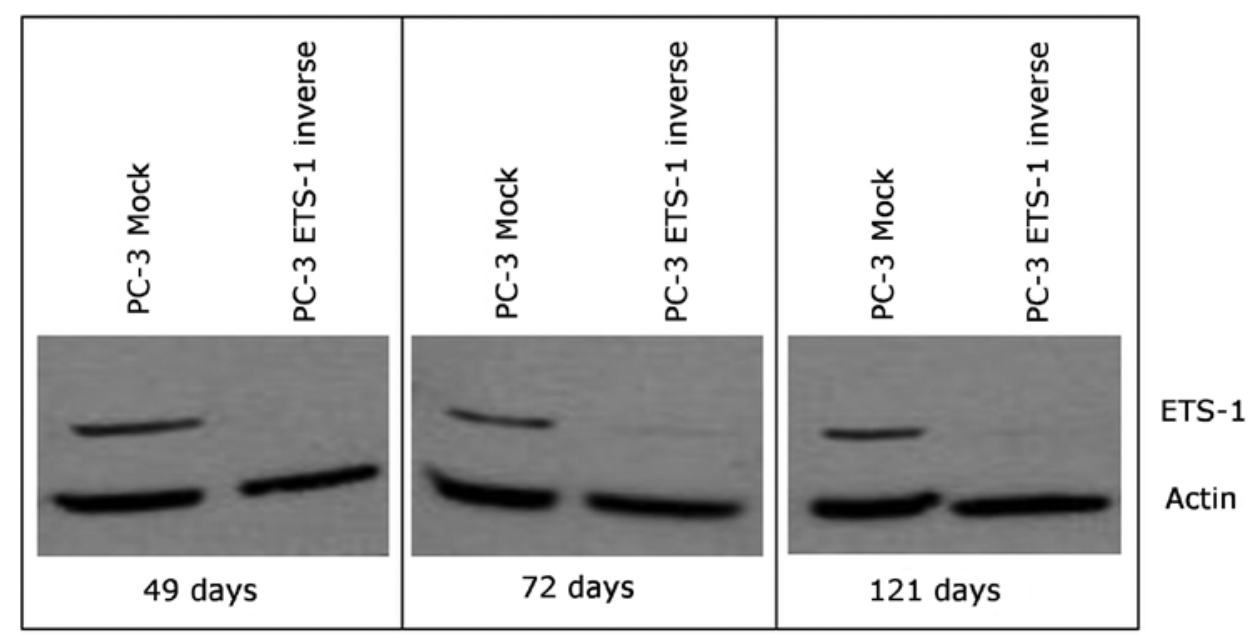

Figure 4. Stable transfection of ETS-1 in PC3 cells. Western blot analysis showing stable transfection over a period of 121 days of PC3 cells with an empty plasmid (mock) and a plasmid carrying ETS-1 inverse (29). 
$\mathrm{Oh}$

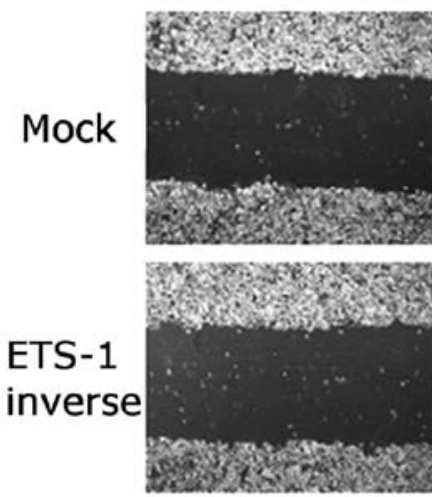

$24 \mathrm{~h}$
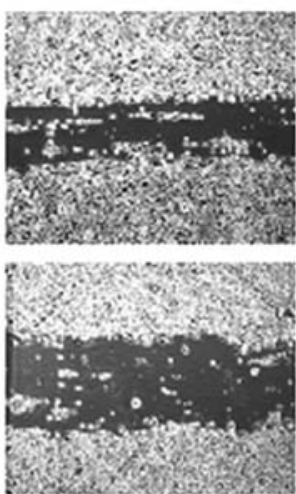

$48 \mathrm{~h}$

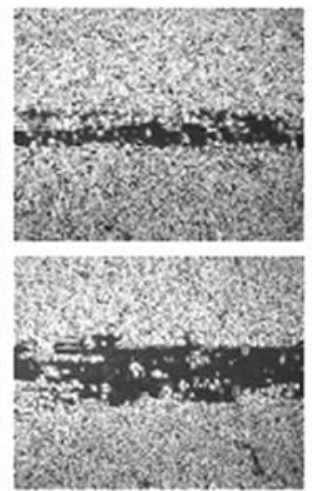

$55 \mathrm{~h}$

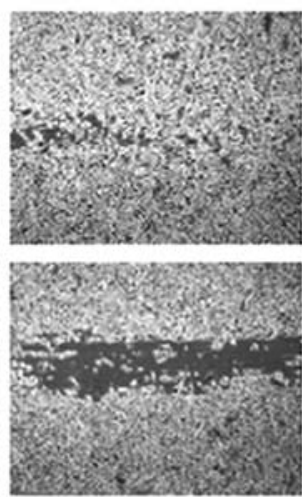

Figure 5. Wound assay: effects of ETS-1 on cell migration. Monolayers of confluent cultures were lightly scratched with a pipette tip and phase contrast images of cultures were taken immediately after wounding $(0 \mathrm{~h})$ and after 24,48 and $55 \mathrm{~h}$. Wounds were almost completely colonized by PC 3 mock control cells in comparison to the PC3 ETS-1 blocked cells after $55 \mathrm{~h}$ (29).

either an ETS-1 inverse antisense expression vector or a mock control vector, and confirmed the blockade of ETS-1 using Western blot analysis (Fig. 4) (29).

We found that blockade of ETS-1 in prostate cancer cells leads to a decrease in cell migration, suggesting a direct role of ETS-1 in this biological property (Fig. 5). However, blockade of ETS-1 did not have a significant effect upon the invasion of the cells (29). These findings indicate that ETS-1 reveals specificity for migration, but not invasion in the prostate cancer PC3 cell line examined (29).

In a follow-up study, we have investigated the effect of blocking ETS-1 in PC3 prostate cancer cells to the expression of genes known to be involved in various steps of the so-called metastatic cascade (such as proliferation, apoptosis, migration and angiogenesis) by a comprehensive gene expression microarray analysis of ETS-1 blocked cells compared to control cells (50).

Our study revealed many differentially expressed genes, however, only the genes with known roles in the metastatic cascade, and an expression of more than 10-fold increase or decrease between the ETS-1 blocked cells and the control were considered significant (50). Correlating these genes with genes found in a microarray analysis of prostate cancer tissues resulted in the identification of 16 genes that are either up- or downregulated in prostate cancer tissues (Tables I and II) (50). Based on previous studies, 4 out of the 16 genes (CD40, IGFBP3, FES and TLR4) have already been reported to be regulated by members of the ETS family (reviewed in ref. 50). A follow-up bioinformatic analysis of these genes revealed that 13/16 of these genes have potential ETS-1 binding sites within their promoters (unpublished data).

As little is known about immune defenses in prostate cancer combined with the fact that the ETS family of transcription factors has been reported to be essential for the regulation of immunity-related genes (reviewed in ref. 51), we recently reported the identification of 37 immunity-related genes in prostate cancer tissues (52). Bioinformatic analysis revealed that 31 of these genes have potential binding sites within their promoter regions for members of the ETS family of transcription factors (52), and a few are known to be targets of ETS members (reviewed in ref. 52).
Table I. Genes that were found to be up-regulated in human prostate carcinomas compared to healthy glands of the prostate proper.

\begin{tabular}{ll}
\hline Gene & \multicolumn{1}{c}{ Full name } \\
\hline PRRX2 & Paired related homeobox 2 \\
ISL1 & ISL LIM homeobox 1 \\
NLRP2 & NLR family, pyrin domain containing 2 \\
BST2 & Bone marrow stromal cell antigen 2 \\
FOXL2 & Forkhead box L2 \\
EGR4 & Early growth response 4 \\
\hline
\end{tabular}

Candidate genes with a fold change of $>2$ and a $\mathrm{P}<0.01$ are shown (50).

Table II. Genes that were found to be down-regulated in human prostate carcinomas compared to healthy glands of the prostate proper.

\begin{tabular}{ll}
\hline Gene & \multicolumn{1}{c}{ Full name } \\
\hline VAV3 & Vav 3 guanine nucleotide exchange factor \\
FES & Feline sarcoma oncogene \\
PYCARD & PYD and CARD domain containing \\
TLR4 & Toll-like receptor 4 \\
IGFBP3 & Insulin-like growth factor binding protein 3 \\
CD40 & CD40 molecule, TNF receptor superfamily \\
& member 5 \\
GAS2 & Growth arrest-specific 2; Fanconi anemia, \\
& complementation group F \\
SNCA & Synuclein, $\alpha$ (non-A4 component of \\
AMOT & amyloid precursor) \\
NPY1R & Angiomotin \\
\end{tabular}

Candidate genes with a fold change of $>2$ and a $\mathrm{P}<0.01$ are shown (50). 


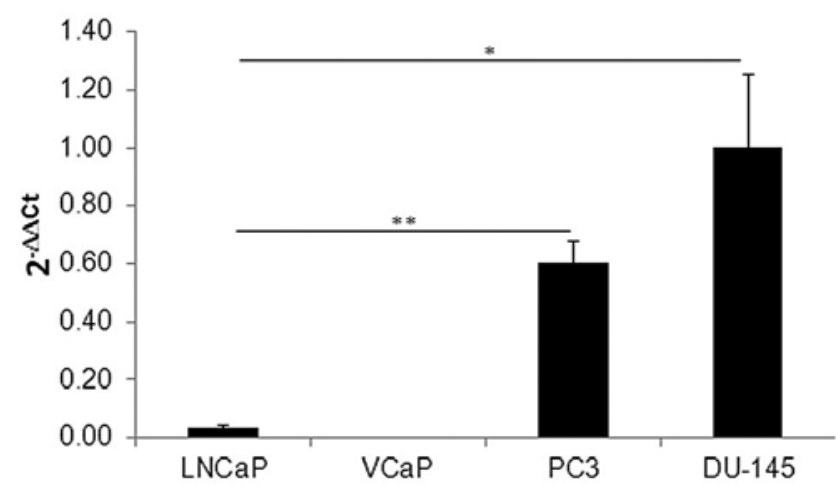

Figure 6. Expression of ETS-1 in prostate cancer cell lines. The relative expression of ETS-1 as measured by qRT-PCR among the DU-145, PC3, VCaP and LNCaP prostate cancer cell lines. Significance was calculated with the Student's t-test. ${ }^{* *} \mathrm{P}<0.01$ and ${ }^{*} \mathrm{P}<0.05$ (45).

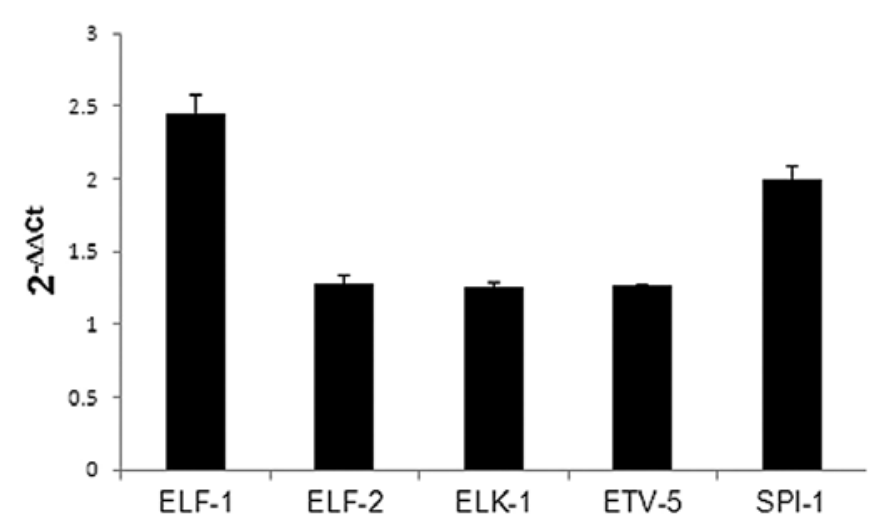

Figure 7. ETS-1 regulates other ETS family members in PC3 prostate cancer cell lines. QRT-PCR analysis using RNA extracted from ETS-1 blocked and mock control PC3 cells shows an up-regulation of the ETS family members $E L F-1, E L F-2, E L K-1, E T V-5$ and SPI-1 in ETS-1 blocked cells compared to mock control (45).

In a follow-up study, we investigated in PC3 prostate cancer cells whether ETS-1 regulates some of these genes (53). We found 6 genes to be down-regulated (BCL11A, CRISP3, $D M B T 1, F G R, N O S 2$ and $S A A 1)$ and 2 genes to be up-regulated (CD38 and HDAC9) in PC3 cells with ETS-1 blockade compared to control cells (53). Our study provided evidence of the involvement of ETS-1 in the activation or repression of immunity-related genes and a potential key role that ETS-1 may play in prostate cancer immunology (53).

\section{ETS-1, a potential regulator of the ETS-family in prostate cancer}

As mentioned previously, the ETS family of transcription factors which has 27 known members in humans, is characterized by a highly conserved DNA-binding domain, the ETS domain, which consists of about 80 amino acids with 4 tryptophan repeats that recognizes DNA sequences containing a GGAA/T core motif (reviewed in refs. 5,19). Despite of the fact that the DNA-binding properties of the ETS members are similar, the different members may have preferences for distinct flanking sequences in the regulatory regions of genes, which may facilitate their binding specificity and subsequently their various functions (20). Furthermore, ETS members can also have overlapping functions, as well as redundant occupancy at proximal regulatory regions of genes $(20,21)$. Therefore, it is plausible that different ETS members may compete for binding to the same ETS-binding sites (EBS) in the regulatory regions of target genes with different affinities (45), and that the trans-activation or trans-repression of genes could be a consequence of dynamic binding equilibrium as well as ternary complex formation of different ETS members and other transcription factors (22). It is conceivable that such a complex regulatory network involving different ETS members as well as ETS fusions could play a role in prostate cancer development and progression (45). Therefore, in a first step to unravel such a complex regulatory network, we have recently investigated whether ETS-1, the prototype of the family, regulates other family members in prostate cancer cell lines (45). We compared the expression level of ETS-1, among the androgen-insensitive DU-145 and PC3 cell lines, as well as the androgen-sensitive $\mathrm{LNCaP}$ and $\mathrm{VCaP}$ cell lines (45). We found ETS-1 to be highly expressed in DU-145 and $\mathrm{PC} 3$ cell lines compared to $\mathrm{LNCaP}$ and $\mathrm{VCaP}$ cell lines (Fig. 6) (45).

As we have previously reported that ETS-1 has an effect upon the biological properties (29) and genes involved in the metastatic cascade in PC3 prostate cancer cells (50), combined with the findings that ETS-1 is highly expressed in PC3 cells (45) (Fig. 6), we investigated the effect of ETS-1 blockade on the expression of the other ETS family members in this cell line (45).

Our study revealed that ETS- 1 selectively regulates the family members $E L F-1, E L F-2, E L K-1, E T V-5$ and SPI-1 in PC3 cells (Fig. 7) (45). Such findings indicate that ETS-1, the prototype of the family, is a potential 'master' regulator of other ETS family members, which could have significant implications in unraveling a complex network of different ETS factors in prostate cancer.

\section{Conclusion}

In prostate cancer, recurrent gene fusions involving members of the ETS family of transcription factors are frequently reported. Studies investigating the role of the ETS family prototype, ETS-1 in prostate cancer provide in vitro and in vivo evidence for the importance of ETS-1 in the development and progression of the disease. Evidence also implicates ETS-1 in prostate cancer immunology, and suggests that ETS-1 may potentially be a master regulator of other ETS family members. These findings do not only underline the importance of ETS-1 in prostate cancer, but also promote the idea that ETS-1 may become a suitable target of novel therapies in the future.

\section{Acknowledgements}

We are grateful to the DFG (Deutsche Forschungsgemeinschaft; German Research Association, grant no. WE 1104/11-1) and the German Cancer Aid (Deutsche Krebshilfe, grant no. 107827) for their financial support. 


\section{References}

1. Leprince D, Gegonne A, Coll J, et al: A putative second cellderived oncogene of the avian leukaemia retrovirus E26. Nature 306: 395-397, 1983.

2. Nunn MF, Seeburg PH, Moscovici C and Duesberg PH: Tripartite structure of the avian erythroblastosis virus E26 transforming gene. Nature 306: 391-395, 1983.

3. Watson DK, McWilliams-Smith MJ, Nunn MF, Duesberg PH, O'Brien SJ and Papas TS: The ets sequence from the transforming gene of avian erythroblastosis virus, E26, has unique domains on human chromosomes 11 and 21: both loci are transcriptionally active. Proc Natl Acad Sci USA 82: 7294-7298, 1985.

4. Hahne JC, Okuducu AF, Sahin A, Fafeur V, Kiriakidis S and Wernert N: The transcription factor ETS-1: its role in tumour development and strategies for its inhibition. Mini RevMed Chem 8: 1095-1105, 2008.

5. Dittmer J: The biology of the Ets1 proto-oncogene. Mol Cancer 2: 29,2003

6. Vandenbunder B, Pardanaud L, Jaffredo T, Mirabel MA and Stehelin D: Complementary patterns of expression of c-ets 1 , c-myb and c-myc in the blood-forming system of the chick embryo. Development 107: 265-274, 1989.

7. Wernert N, Raes MB, Lassalle $\mathrm{P}$, et al: c-ets1 proto-oncogene is a transcription factor expressed in endothelial cells during tumor vascularization and other forms of angiogenesis in humans. Am J Pathol 140: 119-127, 1992.

8. Pourtier-Manzanedo A, Vercamer C, van Belle E, Mattot V, Mouquet $\mathrm{F}$ and Vandenbunder B: Expression of an Ets-1 dominant-negative mutant perturbs normal and tumor angiogenesis in a mouse ear model. Oncogene 22: 1795-1806, 2003.

9. Adam M, Schmidt D, Wardelmann E, Wernert N and Albers P: Angiogenetic protooncogene ets-1 induced neovascularization is involved in the metastatic process of testicular germ cell tumors. Eur Urol 44: 329-336, 2003.

10. Behrens P, Rothe M, Wellmann A, Krischler J and Wernert N: The Ets-1 transcription factor is up-regulated together with MMP 1 and MMP 9 in the stroma of pre-invasive breast cancer. J Pathol 194 43-50, 2001.

11. Behrens P, Mathiak M, Mangold E, et al: Stromal expression of invasion-promoting, matrix-degrading proteases MMP-1 and -9 and the Ets 1 transcription factor in HNPCC carcinomas and sporadic colorectal cancers. Int J Cancer 107: 183-188, 2003

12. Alipov G, Nakayama T, Ito M, et al: Overexpression of Ets-1 proto-oncogene in latent and clinical prostatic carcinomas. Histopathology 46: 202-208, 2005.

13. Hahne JC, Kummer S, Heukamp LC, et al: Regulation of protein tyrosine kinases in tumour cells by the transcription factor Ets-1. Int J Oncol 35: 989-996, 2009.

14. Wernert N, Stanjek A, Kiriakidis S, et al: Inhibition of angiogenesis in vivo by ets-1 antisense oligonucleotides-inhibition of Ets-1 transcription factor expression by the antibiotic fumagillin. Angew Chem Int Ed Engl 38: 3228-3231, 1999.

15. Wernert N, Gilles F, Fafeur V, et al: Stromal expression of c-Ets1 transcription factor correlates with tumor invasion. Cancer Res 54: 5683-5688, 1994.

16. Laudet V, Niel C, Duterque-Coquillaud M, Leprince D and Stehelin D: Evolution of the ets gene family. Biochem Biophys Res Commun 190: 8-14, 1993.

17. Macleod K, Leprince D and Stehelin D: The ets gene family. Trends Biochem Sci 17: 251-256, 1992.

18. Laudet V, Hanni C, Stehelin D and Duterque-Coquillaud M: Molecular phylogeny of the ETS gene family. Oncogene 18 1351-1359, 1999.

19. Wasylyk B, Hahn SL and Giovane A: The Ets family of transcription factors. Eur J Biochem/FEBS 211: 7-18, 1993.

20. Hollenhorst PC, Shah AA, Hopkins C and Graves BJ: Genomewide analyses reveal properties of redundant and specific promoter occupancy within the ETS gene family. Genes Dev 21: 1882-1894, 2007.

21. Wei G, Srinivasan R, Cantemir-Stone CZ, et al: Ets1 and Ets 2 are required for endothelial cell survival during embryonic angiogenesis. Blood 114: 1123-1130, 2009.

22. Wei GH, Badis G, Berger MF, et al: Genome-wide analysis of ETS-family DNA-binding in vitro and in vivo. EMBO J 29 : 2147-2160,2010.

23. Hollenhorst PC, Jones DA and Graves BJ: Expression profiles frame the promoter specificity dilemma of the ETS family of transcription factors. Nucleic Acids Res 32: 5693-5702, 2004.
24. Oikawa T: ETS transcription factors: possible targets for cancer therapy. Cancer Sci 95: 626-633, 2004.

25. Hashiya N, Jo N, Aoki M, et al: In vivo evidence of angiogenesis induced by transcription factor Ets-1: Ets-1 is located upstream of angiogenesis cascade. Circulation 109: 3035-3041, 2004.

26. Rothhammer T, Hahne JC, Florin A, et al: The Ets-1 transcription factor is involved in the development and invasion of malignant melanoma. Cell Mol Life Sci 61: 118-128, 2004.

27. Hahne JC, Okuducu AF, Kaminski A, Florin A, Soncin F and Wernert N: Ets-1 expression promotes epithelial cell transformation by inducing migration, invasion and anchorage-independent growth. Oncogene 24: 5384-5388, 2005.

28. Sahin A, Vercamer C, Kaminski A, et al: Dominant-negative inhibition of Ets 1 suppresses tumor growth, invasion and migration in rat C6 glioma cells and reveals differentially expressed Ets 1 target genes. Int J Oncol 34: 377-389, 2009.

29. Adler D, Langer B, Lindstrot A, et al: Ets-1 is implicated in the regulation of androgen co-regulator FHL2 and reveals specificity for migration, but not invasion, of $\mathrm{PC} 3$ prostate cancer cells Oncol Rep 25: 1125-1129, 2011.

30. Tomlins SA, Rhodes DR, Perner S, et al: Recurrent fusion of TMPRSS2 and ETS transcription factor genes in prostate cancer. Science 310: 644-648, 2005.

31. Rubin MA, Maher CA and Chinnaiyan AM: Common gene rearrangements in prostate cancer. J Clin Oncol 29: 3659-3668, 2011.

32. Kumar-Sinha C, Tomlins SA and Chinnaiyan AM: Recurrent gene fusions in prostate cancer. Nat Rev 8: 497-511, 2008.

33. Tomlins SA, Laxman B, Dhanasekaran SM, et al: Distinct classes of chromosomal rearrangements create oncogenic ETS gene fusions in prostate cancer. Nature 448: 595-599, 2007.

34. Carver BS, Tran J, Chen Z, et al: ETS rearrangements and prostate cancer initiation. Nature 457: E1-E3, 2009.

35. Joshua AM, Evans A, van der Kwast T, et al: Prostatic preneoplasia and beyond. Biochim Biophys Acta 1785: 156-181, 2008.

36. Mehra R, Tomlins SA, Yu J, et al: Characterization of TMPRSS2-ETS gene aberrations in androgen-independent metastatic prostate cancer. Cancer Res 68: 3584-3590, 2008.

37. Perner S, Svensson MA, Hossain RR, et al: ERG rearrangement metastasis patterns in locally advanced prostate cancer. Urology 75: 762-767, 2010.

38. Perner S, Demichelis F, Beroukhim R, et al: TMPRSS2:ERG fusion-associated deletions provide insight into the heterogeneity of prostate cancer. Cancer Res 66: 8337-8341, 2006.

39. Perner S, Mosquera JM, Demichelis F, et al: TMPRSS2-ERG fusion prostate cancer: an early molecular event associated with invasion. Am J Surg Pathol 31: 882-888, 2007.

40. Sun C, Dobi A, Mohamed A, et al: TMPRSS2-ERG fusion, a common genomic alteration in prostate cancer activates C-MYC and abrogates prostate epithelial differentiation. Oncogene 27: 5348-5353, 2008

41. Watson KD, Turner DP, Scheiber MN, Findlay VJ and Watson PM III: ETS transcription factor expression and conversion during prostate and breast cancer progression. Open Cancer J 3: 24-39, 2010.

42. Hollenhorst PC, Paul L, Ferris MW and Graves BJ: The ETS gene ETV4 is required for anchorage-independent growth and a cell proliferation gene expression program in PC3 prostate cells. Genes Cancer 1: 1044-1052, 2011.

43. Helgeson BE, Tomlins SA, Shah N, et al: Characterization of TMPRSS2:ETV5 and SLC45A3:ETV5 gene fusions in prostate cancer. Cancer Res 68: 73-80, 2008.

44. Cai C, Hsieh CL, Omwancha J, et al: ETV1 is a novel androgen receptor-regulated gene that mediates prostate cancer cell invasion. Mol Endocrinol 21: 1835-1846, 2007.

45. Adler D, Lindstrot A, Langer B, Buettner R and Wernert N: Differential expression of ETS family members in prostate cancer tissues and androgen-sensitive and insensitive prostate cancer cell lines. Int J Mol Med 28: 89-93, 2011.

46. Adler D, Lindstrot A, Buettner R and Wernert N: Analysis of laser-microdissected prostate cancer tissues reveals potential tumor markers. Int J Mol Med 28: 605-611, 2011.

47. Park C, Lee I and Kang WK: Influence of small interfering RNA corresponding to ets homologous factor on senescenceassociated modulation of prostate carcinogenesis. Mol Cancer Ther 5: 3191-3196, 2006.

48. Sementchenko VI, Schweinfest CW, Papas TS and Watson DK: ETS2 function is required to maintain the transformed state of human prostate cancer cells. Oncogene 17: 2883-2888, 1998. 
49. Carbone GM, Napoli S, Valentini A, Cavalli F, Watson DK and Catapano CV: Triplex DNA-mediated downregulation of Ets2 expression results in growth inhibition and apoptosis in human prostate cancer cells. Nucleic Acids Res 32: 4358-4367, 2004.

50.Adler D, Lindstrot A, Langer B, Buettner R and Wernert N: Comprehensive gene expression microarray analysis of Ets-1 blockade in PC3 prostate cancer cells and correlations with prostate cancer tissues: Insights into genes involved in the metastatic cascade. Int J Mol Med 27: 811-819, 2011.

51. Gallant S and Gilkeson G: ETS transcription factors and regulation of immunity. Arch Immunol Ther Exp (Warsz) 54: 149-163, 2006.
52. Adler D, Lindstrot A, Ellinger J, Rogenhofer S, Buettner R and Wernert N: Identification of immunity-related genes in prostate cancer and potential role of the ETS family of transcription factors in their regulation. Int J Mol Med 28: 799-807, 2011.

53. Adler D, Lindstrot A, Buettner R and Wernert N: Regulation of prostate cancer immunity-related genes in PC3 prostate cancer cells by ETS-1. Oncol Lett: December 2, 2011. doi: 10.3892/ol.2011.509. 